\title{
Efficacy analysis of the length of entrance on the diffraction of waves behind two breakwaters
}

\author{
Parviz Ghadimi*, Zahra H. Heyvedi, Mohammad A. Feizi Chekab, Mohammad M. Shora \\ Amirkabir University of Technology \\ *Corresponding author E-mail:pghadimi@aut.ac.ir
}

Copyright $\odot$ 2015Parviz Ghadimi et al. This is an open access article distributed under the Creative Commons Attribution License, which permits unrestricted use, distribution, and reproduction in any medium, provided the original work is properly cited.

\begin{abstract}
Any harbor should be protected from incoming waves. However, these waves are always diffracted at the entrance of the harbor and a fraction of the waves enters the harbor area. In the present paper, by the use of Boussinesq equations solved by Mike21 numerical software, a parametric study on the length of entrance of a simple harbor has been conducted and the diffraction of waves after passing the harbor entrance has been analyzed. As a result, the effects of the length of the entrance have been investigated on the safe zone behind the breakwaters of the harbor. To this end, a parameter called angle of safety is defined as a representative of the safe zone. Finally, an equation is presented to describe the behavior of the safe zone with respect to the length of the entrance. It has been observed that the angle of safety has a minimum of 57.5 degrees which increases with respect to the length of entrance which consequently increases the safe area behind the breakwaters.
\end{abstract}

Keywords:Random Wave Diffraction; Breakwater; Mike21, Safe Zone.

\section{Introduction}

In order to create an area of calm water and safe from the sea waves, the combination of breakwaters may be used. However, when a wave encounters any obstacle, its direction changes and its path bends around the obstacle causing it to reach the area behind it. This phenomenon called wave diffraction occurs in the gap between two breakwaters. Therefore, a portion of the incoming waves enters the area behind the breakwaters with smaller amplitude that causes an area of turbulence. This reduces the usable space behind the breakwaters. However, it has been observed that by adding a ledge to the breakwaters, as illustrated in Fig.1, the diffraction of the waves is more focused toward the center of the gap and the diffracted waves are reduced behind the breakwaters.

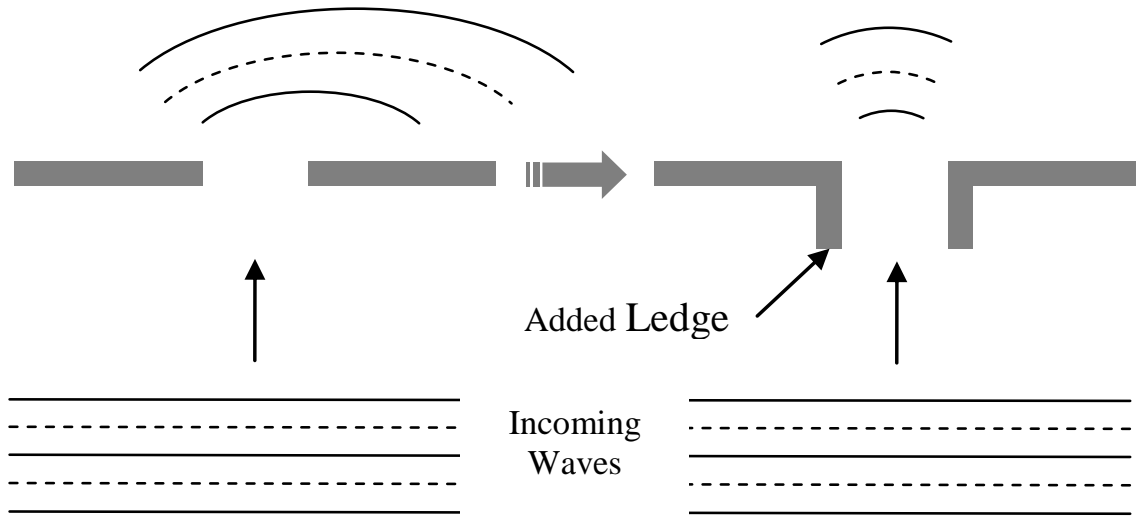

Fig. 1:Geometry of the Validation Model. 
The purpose of the present study is to investigate the effects of the length of these ledges (called as the length of the entrance from now on) on the diffracted waves behind the two breakwaters. To this end, Mike21 software has been used to solve Boussinesq equations for flow around the breakwaters in question.

Several works have been conducted in this field by numerous researchers. A numerical model for studying the effects of directional spreading of random wave propagation and transformation in coastal regions was developed by Dingemans et al 1986 [1]. In 1987, small-scale model tests were performed by Suh and Dalrymple [2] to examine the effects of the geometric parameters of single and multiple offshore breakwaters in a spiral wave basin on the morphological change in their vicinity. Also, another experimental work has been conducted by Pos and Kilner 1987 [3] where breakwater configurations with several gap-to-wavelength ratios have been investigated, and the results were compared with analytical diffraction diagrams given by the Shore Protection Manual. Vincent and Briggs 1989 [4] have also experimentally investigated the directionally spread of irregular waves passing over a submerged elliptical mound.

In 1992, a shoaling, non-breaking, directionally spread wave field has been simulated by Elgar et al. 1992 [5] in a laboratory basin. Also, it should be mentioned that the refraction, shoaling and breaking of multidirectional waves have been investigated by Suzuki et al. 1994 [6] by the use of model test.

A three-dimensional model study of wave diffraction for regular and irregular waves around a semi-infinite breakwater was conducted by Brigges and Thompson 1995 [7]. The results of this work have been used for validations of the present study.

Also, Zyserman et al. 1998 [8] investigated the morphological aspects of the design of shore-parallel breakwaters through a series of tests using a two-dimensional numerical morphological modeling system with mike21 software.

After reviewing the main experimental works on different aspects of breakwaters, the solution of governing equations should be briefly reviewed. These equations, commonly known as Boussinesq equations, were introduced in 1872 by Joseph Boussinesq [9] for approximation of water waves. These equations are valid for weakly nonlinear and long waves. In this approximation, the main idea is to reduce the computational cost by eliminating the vertical coordinate from the flow equations and considering the effects of the vertical flow in other directions. Here, some of the studies conducted in solving and using these equations are briefly introduced.

Modeling the irregular wave propagation on slowly varying bathymetry has been introduced by Madsen and Sørensen 1992 [10] by the use of a new form of the Boussinesq equations. Boussinesq equations have been solved using FiniteElement Method by Y.S. Li et al. 2000 [11]. Wang et al. 2008 [12] presented an expansion of the Boussinesq equations for modeling the propagation and transformation of periodic nonlinear waves (cnoidal waves) in a shallow-water basin. Violante et al. 2009 [13] used SWAN (a wave model introduced by Ilic et al. in 2007 [14]) for approximating the diffraction of waves in a harbor. They presented a Phase-resolving Boussinesq wave model together with measurements conducted on a small-scale model behind a breakwater. Zheng et al 2011 [15] developed WABED which is a nearshorewave transformation model for the wave refraction, diffraction, reflection and wave-current interaction for predicting the irregular wave refraction-diffraction around structures in coastal regions.

After the above introduction, the mathematical formulation of Boussinesq equations is presented in the next section. Afterward, a validation versus experimental data is conducted in section 3 for wave diffraction in the gap between two breakwaters. After introducing the problem setup, the results and discussion of the results are presented in Section 4 which is followed by a conclusion part where the main achievements of the present work are briefly presented.

\section{Mathematical formulation}

As discussed in the introduction, there are many methods for free surface modeling. In this study, the time-domain formulation of the Boussinesq equations is used. This formulation has been introduced and adopted by Madsen et al 1991, 1992 and 1997 [12], [16], [17] and Sorensen et al 2001 and 2004 [19, 20] for wave disturbance in coastal areas. The basis of this method consists of eliminating the vertical momentum equation and solving a three-dimensional problem by considering the effect of vertical accelerations on the pressure distribution in other dimensions. Nonlinearities as well as frequency dispersion are included in the Bousinesq equations.

Momentum equation in $\mathrm{x}$ direction:

$\frac{\partial P}{\partial t}+\frac{\partial}{\partial x}\left(\frac{P^{2}}{h}\right)+\frac{\partial}{\partial y}\left(\frac{P Q}{h}\right)+\frac{\partial R_{x x}}{\partial x}+\frac{\partial R_{x y}}{\partial x}+F_{x} n^{2} g h \frac{\partial \xi}{\partial x}+n^{2} P\left[\alpha+\beta \frac{\sqrt{P^{2}+Q^{2}}}{h}\right]+\frac{g P \sqrt{P^{2}+Q b^{2}}}{h^{2} c^{2}}+n \Psi_{1}=0$

Momentum equation in y direction:

$\frac{\partial Q}{\partial t}+\frac{\partial}{\partial y}\left(\frac{Q^{2}}{h}\right)+\frac{\partial}{\partial x}\left(\frac{P Q}{h}\right)+\frac{\partial R_{x x}}{\partial x}+\frac{\partial R_{x y}}{\partial x}+F_{y} n^{2} g h \frac{\partial \xi}{\partial y}+n^{2} Q\left[\alpha+\beta \frac{\sqrt{P^{2}+Q^{2}}}{h}\right]+\frac{g Q \sqrt{P^{2}+Q^{2}}}{h^{2} c^{2}}+n \Psi_{2}=0$

Continuity:

$\frac{\partial \xi}{\partial t}+\frac{\partial P}{\partial x}+\frac{\partial Q}{\partial y}=0$

Here, the Boussinesq terms $\Psi_{1}, \Psi_{2}$ are defined by 
$\Psi_{1} \equiv-\left(B+\frac{1}{3}\right) d^{2}\left(P_{x x t}+Q_{x y t}\right)-n B g d^{3}\left(\xi_{x x x}+\xi_{x y y}\right)-d d_{x}\left(\frac{1}{3} P_{x t}+\frac{1}{6} Q_{y t}+n B g d\left(2 \xi_{x x}+\xi_{y y}\right)\right)-d d_{y}\left(\frac{1}{6} Q_{x t}+\right.$ $\left.n B g d \xi_{x y}\right)$

(In $\mathrm{x}$ direction)

$\Psi_{2} \equiv-\left(B+\frac{1}{3}\right) d^{2}\left(Q_{y y t}+P_{x y t}\right)-n B g d^{3}\left(\xi_{y y y}+\xi_{x x y}\right)-d d_{y}\left(\frac{1}{3} Q_{y t}+\frac{1}{6} P_{x t}+n B g d\left(2 \xi_{y y}+\xi_{x x}\right)\right)-d d_{x}\left(\frac{1}{6} P_{y t}+\right.$ $\left.n B g d \xi_{x y}\right)$

(In y direction)

Subscripts $\mathrm{x}, \mathrm{y}$, and $\mathrm{t}$ indicate partial differentiations in space and time, respectively. Also, a gradient -stress relation is used to describe the horizontal stress terms as follows:

$F_{x}=-\left(\frac{\partial}{\partial x}\left(v_{t} \frac{\partial P}{\partial x}\right)+\frac{\partial}{\partial y}\left(v_{t}\left(\frac{\partial P}{\partial y}+\frac{\partial Q}{\partial x}\right)\right)\right)$

$F_{y}=-\left(\frac{\partial}{\partial y}\left(v_{t} \frac{\partial Q}{\partial y}\right)+\frac{\partial}{\partial x}\left(v_{t}\left(\frac{\partial Q}{\partial x}+\frac{\partial P}{\partial y}\right)\right)\right)$

where $v_{t}$ is the horizontal eddy viscosity. Here, the terms $R_{x x}, R_{X y}$, and $R_{y y}$ represent the excess momentum originating from the non-uniform velocity distribution due to the presence of the roller and they are defined by the following equations:

$R_{x x}=\frac{\delta}{1-\delta / d}\left(c_{x}-\frac{P}{d}\right)^{2}$

$R_{X y}=\frac{\delta}{1-\delta / d}\left(c_{x}-\frac{P}{d}\right)\left(c_{y}-\frac{Q}{d}\right)$

$R_{y y}=\frac{\delta}{1-\delta / d}\left(c_{y}-\frac{Q}{d}\right)^{2}$

where $\delta=\delta(t, x, y)$ is the thickness of the roller. Also, $c_{x}$ and $c_{y}$ are the components of the roller celerity [17], [21].

This approximation is expected to be valid for water waves and weakly nonlinear waves and also for long waves. The Boussinesq equations are frequently used in coastal engineering for simulating water waves, especially in shallow waters and harbors.

In this study, Mike21 BW has been used to solve the above equations.

\section{Numerical validation and problem setup}

To assess the validity of Mike21 in modeling wave-breakwaters interactions, a gap between two breakwaters has been modeled as illustrated in Fig.2. This setup has been experimentally tested by Yu et al. 2000 [18].

A $260 * 270$ grid with a sizing of $0.1 \mathrm{~m}$ has been used to mesh the numerical domain. As observed in Fig.2, the opening is placed in the middle of the domain. To provide radiation boundary condition at the boundaries, Sponge layers have been used as numerical wave absorbers at the boundaries. The details of the model are presented in Table 1.

Table 1: Model Settings

\begin{tabular}{lll}
\hline Internal Wave Generation & JOHNSWAP Spectrum \\
\hline $\mathrm{N}$ & Number of Sponge Layers & 10 \\
$\mathrm{Bv}$ & Base Value & 5 \\
$\mathrm{Pv}$ & Power Value & 0.5 \\
$L_{0}$ & Wavelength & $1.96 \mathrm{~m}$ \\
$\mathrm{D}$ & Depth & $-0.4 \mathrm{~m}$ \\
$T_{P_{\text {Min }}}$ & Minimum period time & $0.5 \mathrm{~s}$ \\
$T_{t}$ & Run Period & $10 \mathrm{~min}$ \\
$\Delta t$ & Time step & $0.02 \mathrm{~s}$ \\
\hline
\end{tabular}




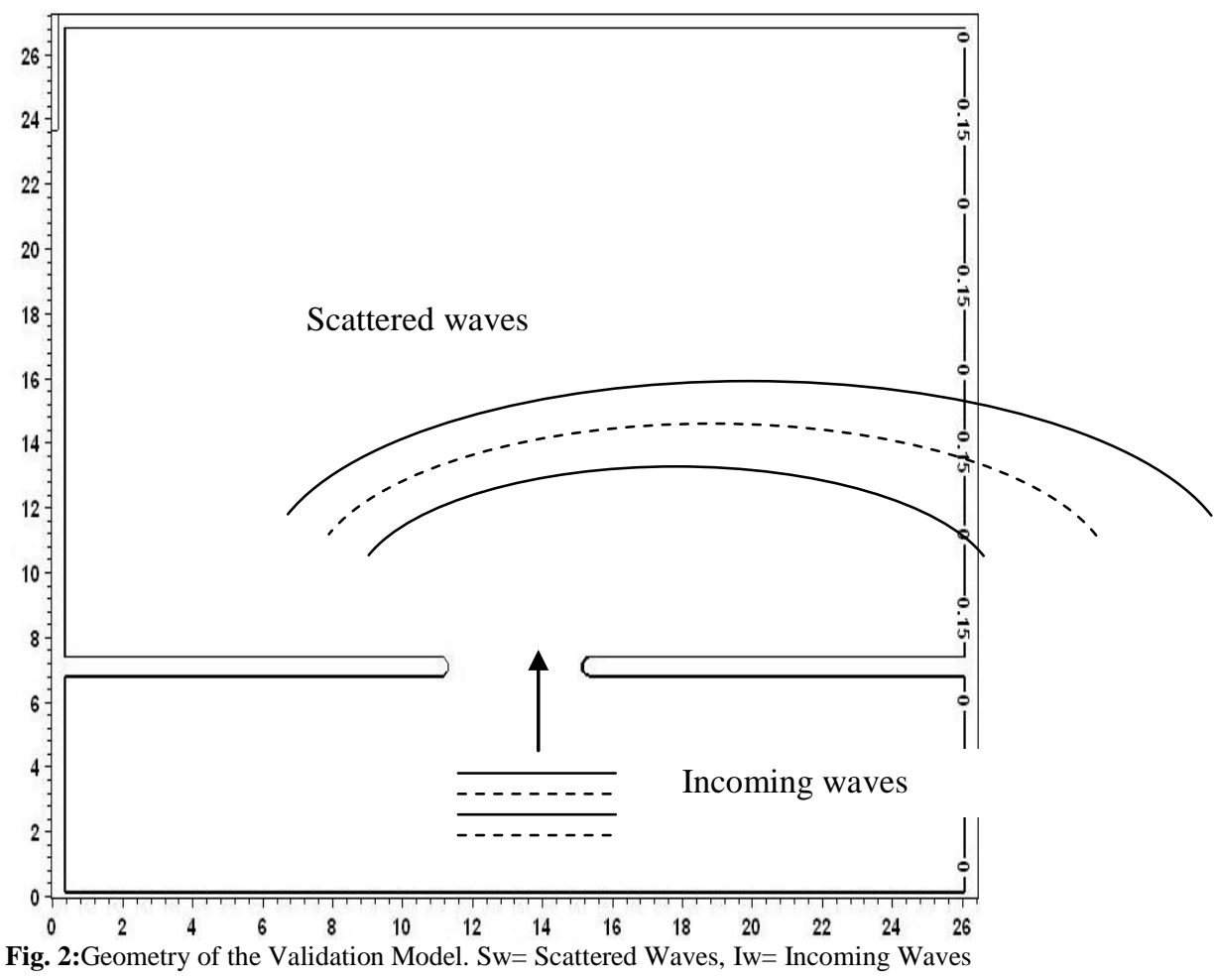

The sponge layer coefficients are calculated using the following formula:

$C_{\text {sponge }}=a^{r^{i-1}} i=1, N_{\text {Sponge }}$

where $\mathrm{a}$ is the base value, $\mathrm{r}$ is the power value and $\mathrm{N}_{\text {Sponge }}$ is the number of sponge lines (counting from the closed boundary towards the first grid line). Also, $\mathrm{L}_{0}$ is the Wave length, $\mathrm{D}$ is water depth, $\mathrm{T}$ is the period time, and Run period is total time of simulation.

The directional spectrum of unidirectional random waves used in this numerical model is generated by Eq.12.

$$
S(f)=\frac{\alpha g^{2}}{f^{5}} e^{\left(-\frac{5}{4}\left(\frac{f p}{f}\right)^{4}\right)} \gamma^{r}
$$

where $r=e^{-\frac{\left(f-f_{p}\right)^{4}}{2 \sigma^{2} f_{p}^{2}}}$ and $\begin{cases}\sigma=\sigma_{a}=0.07 & f \leq f_{p} \\ \sigma=\sigma_{a}=0.09 & f>f_{p}\end{cases}$

In these equations, $\gamma$ is the peak frequency and $\alpha$ is the Philips constant. The peak enhancement factor is equal to 4 . Validation has been conducted for two different wave periods. In both cases, wave direction is normal to the breakwaters. The main specifications of the validation cases are presented in Table 2.

Table 2: Wave Parameters in the Validation Cases.

\begin{tabular}{lllll}
\hline & Wave Type & \multicolumn{1}{c}{$\mathrm{Hm}_{0}$} & Wave Period & Peak Enhancement, $\gamma$ \\
\hline 1 & Unidirectional & $0.05 \mathrm{~m}$ & $0.92 \mathrm{~s}$ & 4 \\
2 & Unidirectional & $0.05 \mathrm{~m}$ & $1.2 \mathrm{~s}$ & 4 \\
\hline
\end{tabular}

Comparison of the current numerical analysis and experimental data presented by Yu et al 2000 [18] is illustrated in Fig.3. This comparison shows good agreement between the model outputs and the experimental data. In this figure, solid lines represent numerical result, while dashed lines represent experimental result by Yu et al 2000 [18].

After the assessment of numerical accuracy of Mike21 in modeling wave-breakwater interaction, the main parametric study has been conducted. As pointed out in the introduction, the purpose of the present study is to investigate the effect of entrance length of a harbor on the diffraction of waves behind its breakwaters. The geometry under investigation is illustrated in Fig.4. 
(a) $\mathrm{B}=3.92, \mathrm{Hm}_{0}=0.05 \mathrm{~m}, \mathrm{~T}_{\mathrm{p}}=1.2 \mathrm{~s}, \mathrm{~B} / \mathrm{L}=2, \gamma=4$;

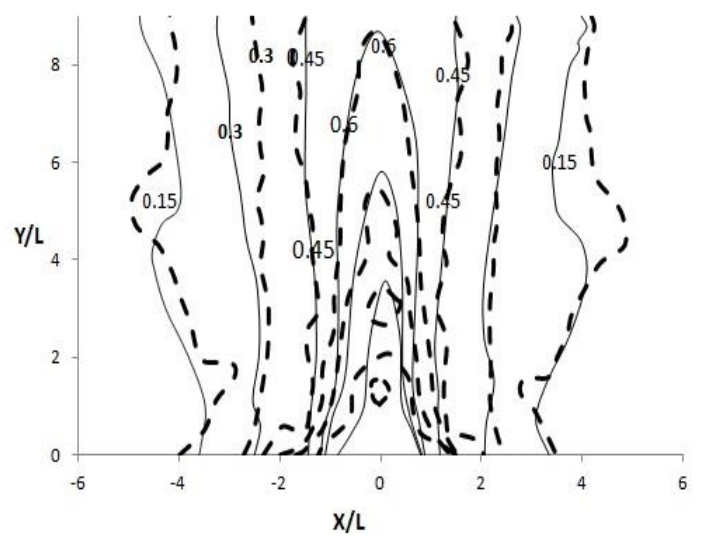

(b) $\mathrm{B}=3.92, \mathrm{Hm}_{0}=0.05 \mathrm{~m}, \mathrm{~T}_{\mathrm{p}}=0.92 \mathrm{~s}, \mathrm{~B} / \mathrm{L}=3, \gamma=4$;

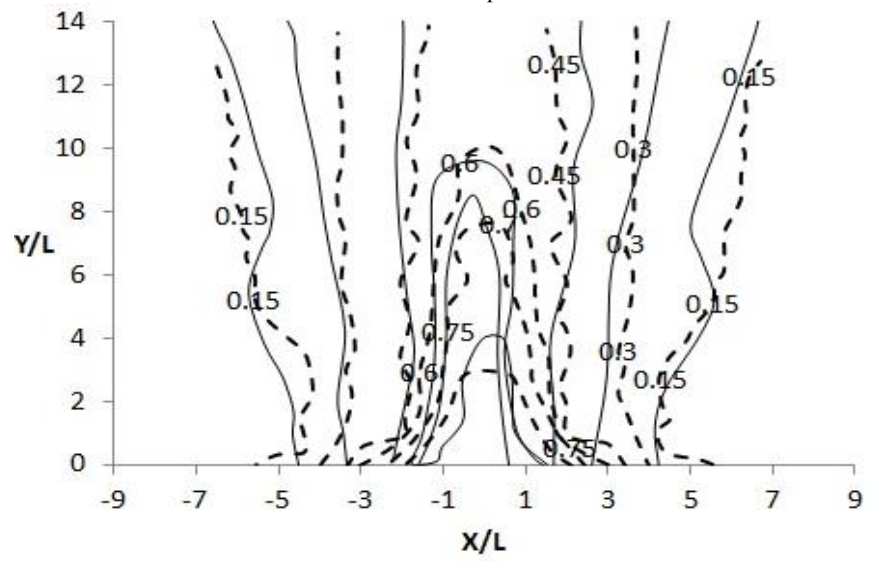

$\mathrm{X} / \mathrm{L}$

Fig. 3:Diffraction Diagrams of Unidirectional Random Waves: $\Gamma=4$.

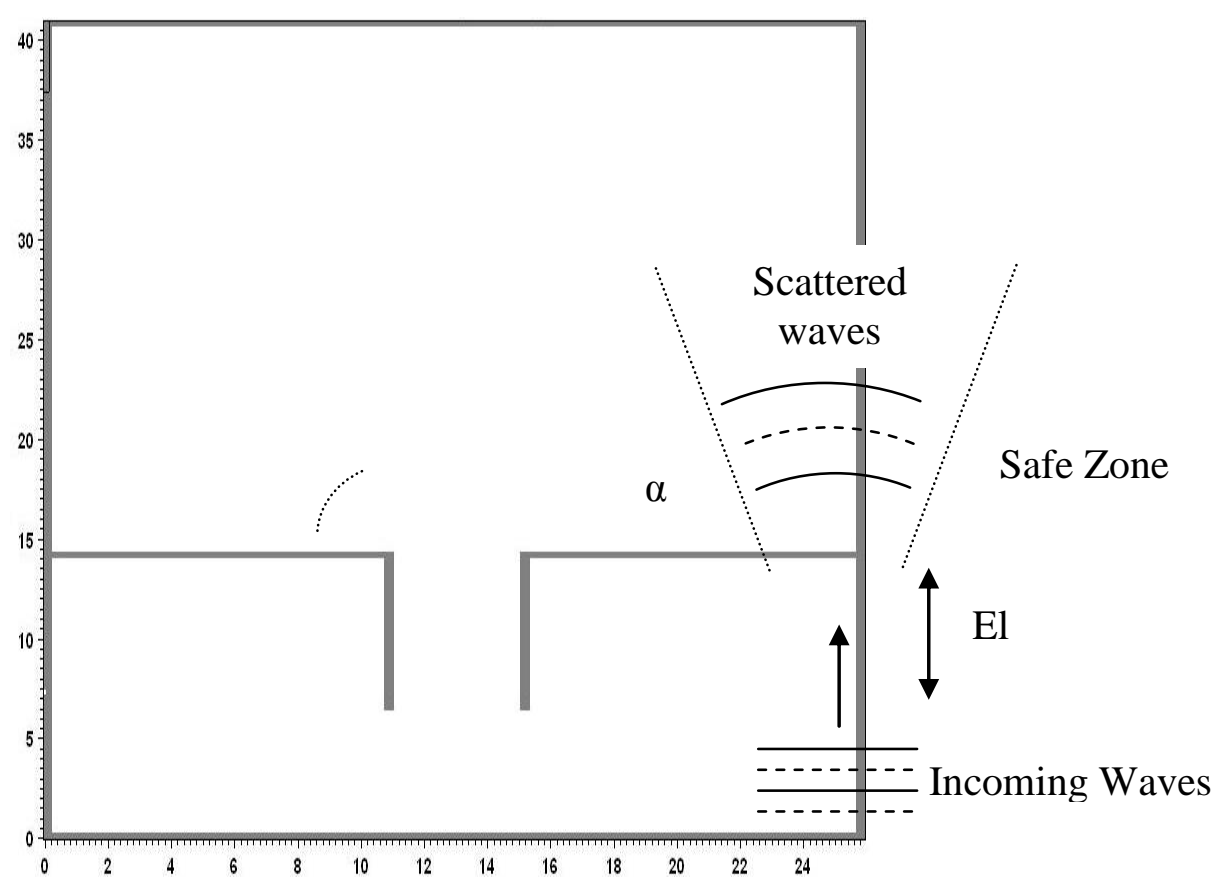

Fig. 4:Schematic View of the Breakwaters Opening Model and Definition of the Safe Zone. El = Entrance Length, A= Angle of Safety.

As illustrated in Fig.4, the entrance length is expected to affect the diffraction of waves behind the breakwaters. To assess these effects, a safe zone is defined where the diffraction coefficient is less than 0.15 . This leads to the definition of the angle of safety, $\alpha$, which is demonstrated in Fig.4. By definition, having a greater angle of safety results in a wider safe zone which is more convenient for sheltering the shoreline. However, the manner in which the entrance length affects the angle of safety needs to be investigated. Therefore, a parametric study is conducted on this issue in the next section.

\section{Results and discussion}

As discussed in the previous section, a parametric study has been conducted on the entrance length of a harbor to assess the effects of this parameter on the angle of safety of the breakwaters. Twenty different cases have been analyzed by changing the entrance length (L) which has a value between $0.2 \lambda$ and $4 \lambda$ where $\lambda$ is the incoming wave length which has been assigned a value of 1.96 meters in all cases. Figure 5 illustrates the results of wave diffraction for six sample cases. 

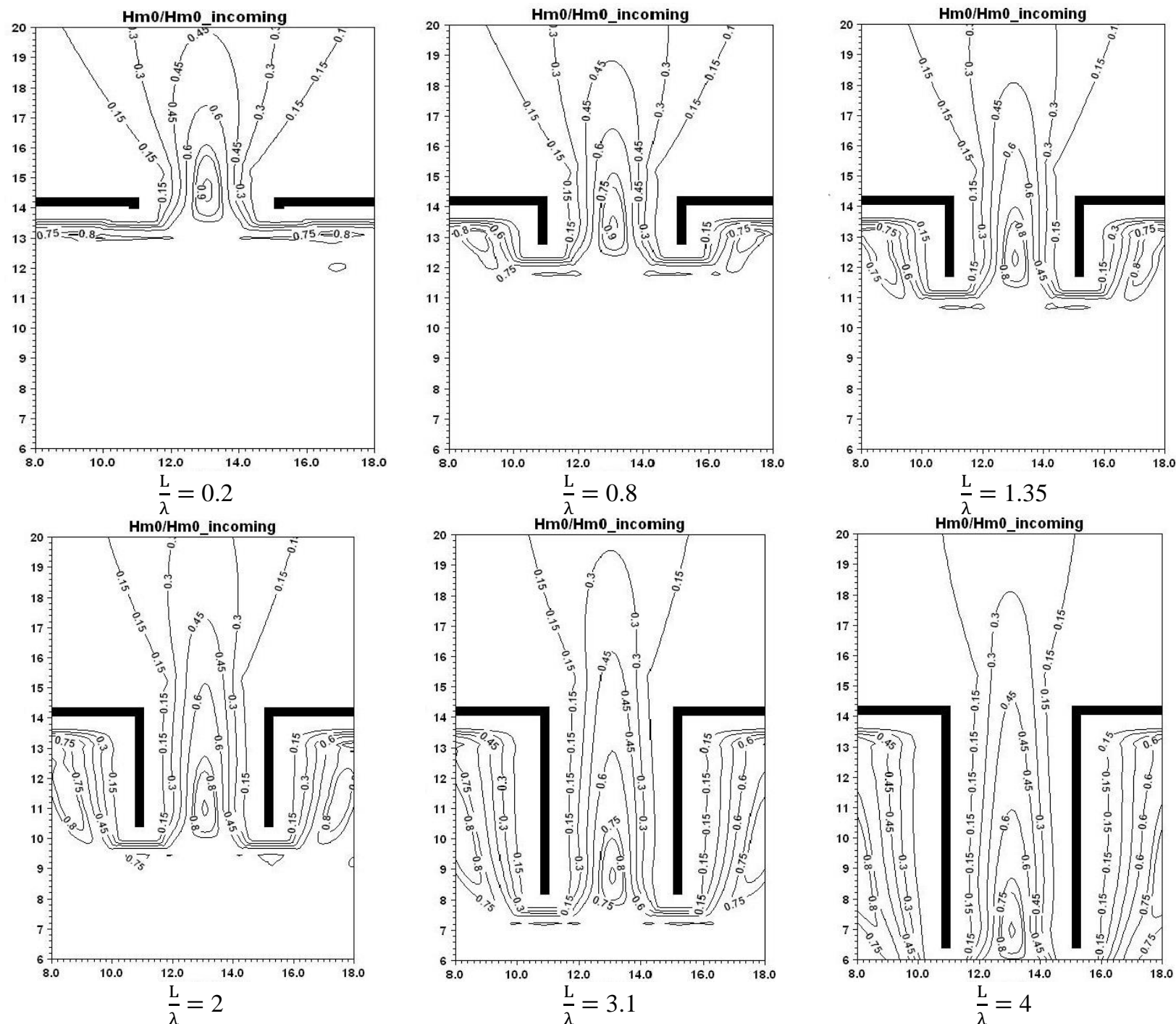

Fig. 5: Diffraction of the Wave for Different Entrance Lengths (6 Cases among 20 Analyzed Cases are Presented), L = Entrance Length, $\Lambda=$ Wave Length.

As observed in Fig.5, as the length of entrance rises, the angle of safety grows and a wider safe zone is obtained behind the breakwaters. To quantitatively assess the effect of the entrance length on the safety zone, a diagram is presented in Fig.6.

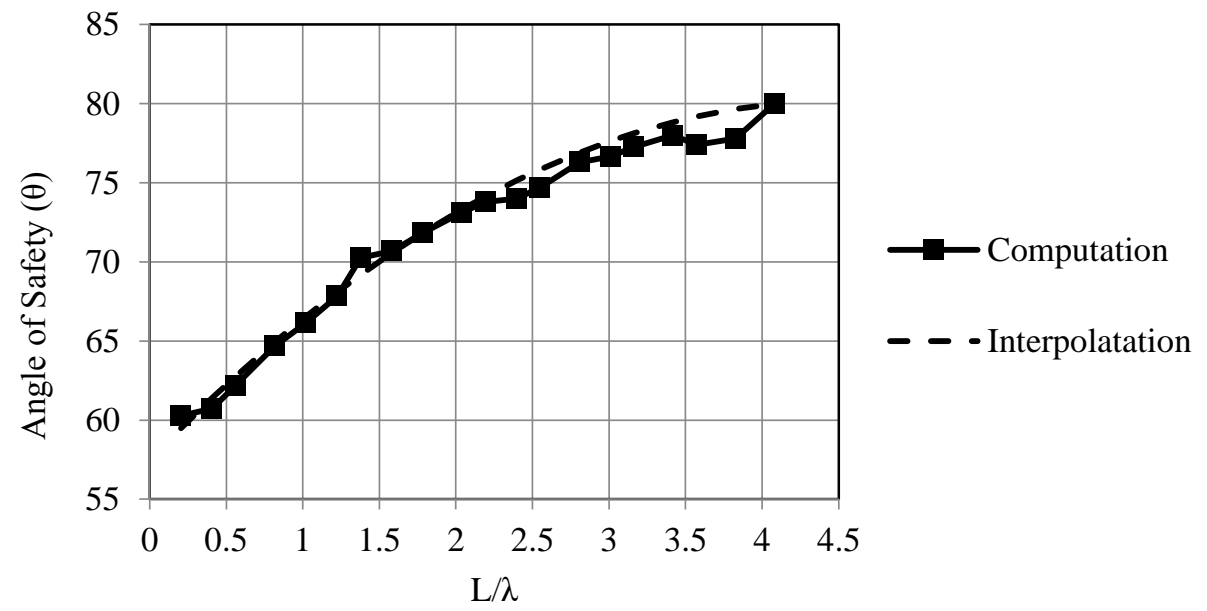

Fig. 6: Angle of Safety Versus $\frac{L}{\Lambda}$. 
It is observed in Fig. 6 that for a constant opening width of the breakwaters, the angle of safety increases with respect to. $\frac{\mathrm{L}}{\lambda}$. This increase seems too converge to a number which his 90 degrees for a high enough $\frac{\mathrm{L}}{\lambda}$. However, there should be a limit for this value because of the application considered in this study.

To better describe the behavior of the angle of safety with respect to $\frac{\mathrm{L}}{\lambda}$, equation 13 is extracted by defining a trend line on the diagram in Fig. 6 whose equations is found to $\mathrm{b} e$

$\theta=-1.1\left(\frac{L}{\lambda}\right)^{2}+10 \frac{L}{\lambda}+57.50 \leq \frac{L}{\lambda} \leq 4$

\section{Conclusions}

It is very important for a harbor to be safe from the incoming waves. Therefore, most harbors use breakwaters to protect the shoreline. However, the gap between the breakwaters allows in a portion of the waves inside the harbor which may decrease the usable or safe space behind the breakwaters. In the present paper, a safe zone behind the breakwaters has been defined where the diffraction of waves is less than 0.15 . Furthermore, the geometry of the safe zone has been defined by a key parameter named angle of safety. Different lengths of the entrance of the harbor have been considered and the effect of increasing the length of the entrance has been investigated on the angle of safety and the safety zone. Calculations have been conducted using Mike21 as a strong Boussinesq equations solver. This solver has been validated by implementing the diffraction of waves passing through an opening between two breakwaters and comparing the results with available experimental data.

It has been shown that the angle of safety has a minimum of approximately 57.5 degrees, which is constant for small lengths of entrance. However, the angle of safety increases with respect to length of the entrance. Finally, an equation has been introduced to calculate the angle of safety with respect to the length of entrance for application in harbor design.

\section{References}

[1] M.W, Dingemans, "Directional near shore wave propagation and induced currents", Proceedings of 20th International Conference of Coastal Engineering, ASCE, New York, (1986), pp.1092-1106. https://icce-ojs-tamu.tdl.org/icce/index.php/icce/article/viewFile/4082/3764.

[2] K.Suh, R.A .Dalrymple, "Offshore breakwaters in laboratory and field", Journal of Waterway, Port, Coastal, Ocean Engineering, ASCE, New York. Volume 113 (2), (1987), pp. 105-121.http://dx.doi.org/10.1061/(ASCE)0733-950X(1987)113:2(105).

[3] D. John Pos, F.A. Kilner, "Breakwater Gap Wave Diffraction: an Experimental and Numerical Study", Journal of Waterway, Port, Coastal, Ocean Engineering, Volume 113(1), (1987), pp. 1-21.http://dx.doi.org/10.1061/(ASCE)0733-950X(1987)113:1(1).

[4] C.L. Vincent, M.J. Briggs "Refraction-diffraction of irregular waves over a mound", Journal of Waterway, Port, Coastal, Ocean Engineering, Volume. 115 (2), (1989), pp.269-284.http://dx.doi.org/10.1061/(ASCE)0733-950X(1989)115:2(269).

[5] S. Elgar, R.T Guza,. M.H. Freilich, M.T. Briggs, "Laboratory simulations of directionally spread shoaling waves" Journal of .Waterway, Port, Coastal, Ocean Engineering, ASCE, Volume 118 (1), (1992), pp. 87-103.

[6] Y.Suzuki, T. Hiraishi, T. Takayama, N.Ikeda, "Applicability of multi-directional wave experiment for port design", Proceedings of the International Conference on Hydro-technical Engineering for Port and Harbor Construction, (1994), pp.281-301.

[7] M. Briggs, E. Thompson, C. Vincent, "Wave Diffraction around Breakwater",Journal Waterway, Port, Coastal, Ocean Engineering, Volume 121 (1), (1995), pp. 23-35. http://dx.doi.org/10.1061/(ASCE)0733-950X(1995)121:1(23).

[8] J.A. Zyserman, I. Broker, H.K. Johnson, K. Mangor, K. Togensen, "On the Design of Shore-Parallel Breakwaters", Journal of Coastal Engineering, (1998), pp. 1693-1705.

[9] J. Boussinesq, "Théorie des ondes et des remous qui se propagent le long d'un canal rectangulaire horizontal, encommuniquant au liquidecontenudansce canal des vitessessensiblementpareilles de la surface au fond", Journal de MathématiquesPures et Appliquées. DeuxièmeSérie 17, (1872), pp.55-108.

[10] A. Madsen, R. Sorensen "A new form of the Boussinesq equations with improved linear dispersion characteristics, Part 2: A slowly-varying Bathymetry", journal of Coastal Engineering, Volume 18, , (1992), pp. 183-204.

[11] Y.S. Li., S.X. Liu., Y.X .Yu., G.Z .Lai., "Numerical modeling of multi-directional irregular waves through breakwaters" Journal ofApplied Mathematical Modeling, Volume 24 , Issues 8-9, (2000), pp. 551-574.http://dx.doi.org/10.1016/S0307-904X(00)00003-2.

[12] K.H .Wang, W. Li, H.S. Lee, "Propagation and transformation of periodic nonlinear shallow-water waves in basins with selected breakwater systems", Journal of Computers \&Fluids, Volume 37, 2008$)$, pp.931-942. http://www.sciencedirect.com/science/article/pii/S0045793007001946.http://dx.doi.org/10.1016/j.compfluid.2007.10.007.

[13] N.V. Carvalho, R.B. Paes-Leme, D.A. Accetta., F. Ostritz, "Diffraction and reflection of irregular waves in a harbor employing a spectral model", Journal ofAnais da Academia Brasileira de Ciências,Volume 81(4), (2009), pp. 837-848.http://dx.doi.org/10.1590/S000137652009000400019 .

[14] Ilic S., van der Westhuysen A.J., Roelvink J.A., Chadwick A.J., "Multidirectional wave transformation around detached breakwaters", journal ofCoastal Engineering, Volume 54, (2007), pp.775-789.

[15] J. Zheng, N.V. Thanh, Z. Chi, "Spectral wave transformation model for simulating refraction-diffraction with strongly reflecting coastal structures" Journal of ActaOceanologicaSinica, Volume 30 (2), (2011), pp.25-32. http://link.springer.com/article/10.1007\%2Fs13131-0110102-y.http://dx.doi.org/10.1007/s13131-011-0102-y.

[16] Per A. Madsen,R. Murray, Ole R. Sorensen "A new form of the Boussinesq equations with improved linear dispersion characteristics" , journal of Coastal Engineering, Volume 15, , (1991), pp. 371-388. http://www.sciencedirect.com/science/article/pii/037838399190017B

[17] P. A. Madsen, O. R. Sorensen, H.A Schaffer "Surf zone dynamics simulated by a Boussinesq type model. Part I. Model description and cross shore motion of regular waves", journal of Coastal Engineering, Volume 32, (1997), pp. $255-287$. http://www.sciencedirect.com/science/article/pii/S0378383997000288 
[18] Y.X .Yu, S.X. Liu, Li, Y.S. Wai O.W.H., "Refraction and diffraction of random waves through breakwater", Journal of Ocean Engineering, Volume 27, (2000), pp.489-509. http://dx.doi.org/10.1016/S0029-8018(99)00005-0.

[19] O.R. Sorensen, L.S. Sorensen, "Boussinesq type modeling using unstructured finite element techniqe", Journal of Coastal Engineering, (2001), pp. 190-202. http://ascelibrary.org/doi/abs/10.1061/40549\%28276\%2915.

[20] O.R. Sorensen, H.A. Schaffer, L.S. Sorensen, "Boussinesq type modeling using unstructured finite element techniqe", Journal of Coastal $\begin{array}{llllll}\text { Engineering, } & \text { Volume } & 50 & \text { (2004), } & \text { pp. } & 181-198 .\end{array}$ http://www.sciencedirect.com/science/article/pii/S0378383903001121.http://dx.doi.org/10.1016/j.coastaleng.2003.10.005. 